\title{
PLACE NAMES IN MULTICULTURAL SOCIETIES
}

\author{
THOMAS HYLLAND ERIKSEN \\ University of Oslo
}

\section{A B S TRACT}

It is not unthinkable that in a not too distant future, citizens of Oslo will have the opportunity to meet for appointments at Salimi Square, to shop for vegetables in Kharian Street, to enjoy their picnics in Rubina Rana Park and to drive to the nearby town of Drammen on Mogadishu Road.

Historical change may lead to politically motivated changes in place names, although often slow and uneven, and major upheavals such as revolutions tend to entail a total renovation of the names of streets, parks and other urban fixtures. The names of towns and villages tend to stick more stubbornly. This short essay looks at these three modes, drawing on examples from Tehran, Trinidad and Toronto, eventually relating them tentatively to the emergent multiethnic reality in Oslo and the future prospects for place names in the city.

\section{[1] INTRODUCTION}

While semantics has a long history in social anthropology and related disciplines (see e.g. Parkin 1983), and personal names have been studied by Alford (1988), Geertz (1973) and others, the semantics of place names has rarely been studied by anthropologists or other social scientists interested in identification. Perhaps this is because the issues of place names may superficially appear to be irrelevant to social processes. The significance attached by people to geographical names can often be put down simply to mental associations with no direct connection to the actual name. Most people are oblivious of, or indifferent to, the etymology or origin of a particular place name, giving it emotional or cognitive significance on the basis of personal knowledge or experiences. Few give much attention to the historical connection of New York to the north English city at the confluence of the Ouse and the Foss (or the fact that the great world city was, in an earlier stage of colonialism, called New Amsterdam); and London is far better known for its pubs and double-decker buses than its Latin origin as Londinium (incidentally, some scholars have unearthed an even older etymology linking it to a certain preRoman chieftain bearing the moniker King Lud).

In Norway, few natives of Kristiansand think seriously about implications of their hometown being named after King Christian IV (1577-1648); and few are even aware that the smaller town Kristiansund was named after another, less well 
known Dano-Norwegian king, namely Christian VI (1699-1746). In the capital Oslo, however, the city's name, originally honouring Christian IV, was changed for political reasons from Kristiania in 1925: it became ideologically imperative for the country to have a capital city with a historical lineage pointing backwards, not towards the long period when Norway was a mere Danish province, but beyond to the Middle Ages, when Norway had been an independent kingdom of European significance (Wetås 2000).

Presumably, not a few inhabitants of Oslo (and of Norway) would have reflected critically on the change of name in the first years after its adoption, and the debate ending in the final decision to change the name of Kristiania, taking place both in the City Council and in the Parliament, had been long and passionate. Deliberately changing a historical place name is a dramatic act which is highly likely to lead to controversy and disagreement, disregarding the particular circumstances.

Changes in place names may reflect new political circumstances (Volgograd to Stalingrad and back; St. Petersburg to Leningrad and back, etc.), but can also be caused by changes in the population. When new place names are needed, as in recently built suburbs of modern cities, careful deliberation is often needed to capture the genius loci in ways presumed to be acceptable for the public in the years to come. At the Oslo university campus at Blindern, which was largely built after the Second World War, a treacherous, winding road connecting different parts of the campus was simply named Problemveien ('Problem road') after years of languishing in the no-man's land of bureaucratic register numbers (for years, it was merely called Road 1074 or some such thing). In 2005, as part of her campaign to be elected as Rector, Prof. Fanny Duckert unsuccessfully tried to rename the road Løsningsveien ('Solution road').

In new Oslo suburbs, dating from the 1950s onwards, many more or less imaginative streetnames have established themselves in the popular mind, ranging from Ole Brumms vei ('Winnie the Pooh road', located very near Kristoffer Robins vei, by the way) and Kortbølgen, Mellombølgen and Langbølgen ('The Short Wave', 'The Medium Wave' and 'The Long Wave' - this clump of streets was located near a large radio transmitter) to descriptive names denoting landscape features and street names solemnly commemorating great men (and a few women), urban planners among them, but also people like the UN's first general secretary Trygve Lie, whose Trygve Lies plass is appropriately the main square of Furuset, the area where Lie grew up in the beginning of the 20th century - then a semi-rural cluster of wooden villas just outside the city, now a bustling suburb connected to the city by metro - appropriate because, as it happens, the majority of Furuset's population has a minority background and can thus be depicted, with no acrobatic leap of the imagination, as a mini-United Nations. 
Transitions are rarely as smooth and successful as this - nobody could have known, when Trygve Lie Square was named in the 1960s, that most of the people walking across it in the early 21st century would have a non-Norwegian background, yet the name seems perfectly appropriate and indeed, at a time when xenophobia and a culture of suspicion surrounding the new demography are rife, can work a reminder of the fact that all of Norwegian history has not been centred on ethnic nationalism; in fact, that cosmopolitanism has a fairly substantial lineage even in this remote corner.

Changing the names of streets or squares, or inventing new names for new locations, is never uncontroversial (see Ainiala (2000) for Finland, Abramowicz \& Dacewicz (2009) for Poland). Place names give a Heimatsgefühl, a sense of belonging and attachment. Attributing names to physical entities is generally a task left to gods (indeed it seems to be one of their main duties), but today it has increasingly become the domain of city councils and municipal administrations. Seen against this backdrop, it becomes evident that the responsibility of naming represents a substantial challenge, and - one might add - this is more evident than perhaps ever before in our era of transience and complexity, when local inhabitants represent different cultural backgrounds, local history bifurcates and the cultural identities of the population cannot even be expected to remain stable in the years to come.

It may well be that future citizens of Oslo will have the opportunity to meet for appointments at Salimi Square, to shop for vegetables in Kharian Street, to take their picnics in Rubina Rana Park and to drive to Drammen on Mogadishu Road. (Salimi is the family name of two siblings originally from Lahore, Khalid and Fakhra, who have pioneered antiracism and cosmopolitan values in Norway since the late 1970s; Kharian is the area in Pakistani Punjab where most of Norway's more than 30,000 Pakistani immigrants originate; Rubina Rana, a PakistaniNorwegian woman, was the first non-white Norwegian to chair the 17 May (Constitution Day) committee in Oslo.) However, resistance to such changes can be stubborn and vehement, as witnessed in the many unsuccessful initiatives over the years to have a street or small square in Oslo named after Knut Hamsun, one of the country's finest novelists but also a man widely seen as a traitor to the nation because of his open sympathies for the German occupying forces during the Second World War.

Historical change may eventually lead to change in place names, although this need not happen, and if it does, it is normally the work of a megalomaniac dictator or the grinding machinery of local politics, and major upheavals such as revolutions tend to entail a total renovation of the names of streets, parks and other urban fixtures. The names of towns and villages tend to stick more stubbornly.

On this background, it may be interesting to take a brief look at some of the processes which have actually led to changes in (and the devising of new) local 
names, and the name situation in old multicultural societies, to see if it may be worthwhile to extrapolate from recent historical experiences to a possible future for an increasingly multiethnic Norwegian capital.

\section{[2] TORONTO}

Canada is known for practising one of the most inclusive multicultural policies in the world, in the sense that considerable effort is made to create a common national space that does not discriminate on the basis of ethnicity or religion. Along with Montreal and Vancouver, Toronto is the most multicultural city in one of the world's most overtly and self-consciously multicultural countries.

Street names in Toronto still have old names (many going back to the 18th and 19th century), and there have been few changes in spite of a problem arising from the extension of the city boundaries in 1996, leading to over a hundred duplicate street names. Yet, a certain tendency can be observed, as when a street was renamed Hakim Street, after the founder of Hakim Optics, in 2008. However, on the whole, Toronto streets remain 'very Anglo', as one commentator put it. The city authorities have a conservative policy on renaming, stating in no uncertain terms that 'The general policy is that the names of streets and lanes should not be changed.' However, in the list of criteria for the naming of streets as such, the fifth and final point states that a street name may be justified if it can lead 'to recognize communities which contribute to the ethno-racial diversity of Toronto'. This has already led to some debate in the city concerning possible solutions to the duplicate problem.

Regarding quarters and urban areas, the City Council has been considerably less conservative than with street names proper. In the 1980s, it decided that the names of important locations and urban regions should reflect the recent (and evolving) multiethnic situation in the city. One part of downtown Toronto was solemnly baptised Little Italy, complete with a small Italian flag adorning the placard. There is also Gerrard India Bazaar, Greektown, Portugal Village, Korea Town and, of course, Chinatown. In these quarters, the legitimate street names still appear, although sometimes bilingually, but are superimposed by a sign and a small symbol indicating the ethnic designation of the quarter.

In a city with considerable mobility both internally and externally, such policies are not introduced without a certain risk. Bureaucracies everywhere tend to be sluggish in implementing plans which in turn have been decided in painstaking and cumbersome ways by councillors, and by the time the new names were in place, the ethnic composition of the city had changed somewhat. When I visited Toronto in 1988, after having been impressed by the twelve-language municipal flier distributed to all households and announcing reduced rubbish collection during the summer break, I biked down to Little Italy only to discover that it ap- 
peared to be a very West Indian neighbourhood. My fellow cyclists (Portuguese and Ukrainian, as it happens, but simultaneously a hundred per cent Canadian) explained that most of the Italians had moved up the social ladder and bought condominiums in a different part of the city. The Italian cafes and restaurants were still intact, though.

The case of Toronto reveals a willingness, among the city authorities, to tamper with the symbolic universe enabling the inhabitants to develop a sense of home; or, put differently, to adjust the map to make it fit the territory better. Yet, we should note that changes in street names appear to take much longer, and to be more difficult to achieve, than changes in the designation of urban quarters. In fact, no major Western city has so far, to my knowledge, changed the names of many streets, parks and squares following immigration. The likelihood that they will in the future is nonetheless considerable, given that local place names do change as society does, but slowly. More commonly, however, new place names appear with new places or following dramatic upheavals and political change.

\section{[3] TEHRAN}

The latter is what happened in Tehran following the Islamic revolution in 1979. Street names, to which considerable importance is always attached, can have strong political connotations. No German city has an Adolf-Hitler-Strasse today, while virtually all of them had one in 1940. Similarly, the number of streets named after Joseph Stalin in Russia declined sharply after 1991. In the republics of the former Yugoslavia, where the relationship to the socialist federation is generally less unequivocal than in the ex-Soviet Union, a number of streets and squares are still named after Josip Broz Tito, although many have been renamed; and it is probably no coincidence that these names are most common in Croatia (Tito was a Croat) and Bosnia-Hercegovina (the republic that suffered the most from the breakup of the country).

Street names can be contested. In Belfast, someone pointed out to me, 'everywhere you go, you are reminded of British imperialism'. There is Cromwell Avenue, Churchill House, Queen Elizabeth Bridge, the King's Hall, the Royal Victoria hospital and scores of other examples of localities reminding the inhabitants of Belfast of Northern Ireland being politically a part of the United Kingdom. Naturally, all other things being equal, these place names mean something very different to a Protestant than to a Catholic.

In Tehran before the revolution, streets and avenues were often named after international leaders such as Roosevelt and churchill - in fact, a surprising number of Third World cities have an imposing Roosevelt Avenue, or, in a number of cases, had one until the name was changed to honour the current president. In the case of Tehran, many local place names would change in the years following 
the revolution (Feizabad \& Abbasi 2009). The largest square and busiest traffic hub in the city is now called Imam Khomeini Square, and a great number of other street names have also changed.

At the same time, popular usage does not always correspond to official naming, especially in societies where oral communication tends to take precedence over the written word. A fact sometimes mentioned by foreigners visiting Tehran is that locals still tend to use the pre-revolutionary names, and are in many cases oblivious of the new ones. In a number of cases, a third, informal name is the most common reference. Khalid Islambouli Street, which is a rather posh street in North Tehran, was renamed Intifada Street some years ago, but taxidrivers and locals know the street under the name Vozara Street, meaning 'Ministers' street'. This is explained by the fact that several government ministers used to live there a few decades ago.

Several interesting controversies over renamed streets have taken place around Islamic Iran (although they have rarely been enacted publicly in the country). The aforementioned Khaled Islambouli was in fact the assassin of Egypt's secular and Western-oriented president Anwar Sadat, and naming the street after him clearly reflected the bad diplomatic relations between Egypt and post-revolutionary Iran. The official renaming of the street, after twenty-five years of honouring Sadat's murderer, in order to honour Palestinian martyrs instead, must be understood in the wider context of diplomatic thaw.

A deeper and more enduring conflict was expressed through the renaming of Churchill Street to Bobby Sands Street; all the two men had in common, it could be argued, was living in the same century, having the same gender and hailing from the same part of the world. Robert 'Bobby' Sands (1954-81) was an IRA militant who had devoted his life to fighting the British state and the local Unionists, seeing the former as an occupying force and the latter as traitors. Imprisoned in 1977, Sands died at the age of 26 in a Belfast prison during a hunger strike. On the official blue and white street sign denoting 'Bobby Sands Street', the words 'militant Irish guerilla' appear in English underneath the name of the street. As if this weren't enough of a provocation to the main accomplice of the Great Satan, the city authorities made certain to locate Bobby Sands Street so that the British Embassy would be located there, hoping no doubt for an official letterhead giving Bobby Sands Street as the address of the Embassy. However, following the local practice of maintaining usage of obsolete street names, the Queen's representatives erroneously state their street address as Ferdowsi Avenue (under which name the street is popularly known anyway).

If the Iranian example is anything to go by, changed street names may just as well be used to honour enemies of one's enemies as one's famed sons and daughters. This practice may have been followed in Albania and possibly the Soviet Union during the Cold War, but I have been unable to find good examples. Besides, 
to my knowledge, no country has yet had the nerve to announce the inauguration of Osama bin Laden Street.

\section{[4] TRINIDAD}

In Toronto, the composition of the population has changed rapidly (from largely Anglo-White to nearly 50\% immigrants from all over the world); in Iran, the revolution heralded a new beginning and a need to leave the recent past as far behind as possible - in both cases, names of localities have come under scrutiny and have in some cases been changed. My third example, or vignette, is different. The Caribbean island-state of Trinidad and Tobago has a multilayered history, but scarcely a homogeneous, simple past when society was 'authentic' and devoid of modern decadence and complexity. Well, actually, there is a small group of Trinidadians claiming Amerindian descent, but neither do others take them very seriously, nor do they encourage everybody else to 'go home'. The history of Trinidad (Tobago has a different history and must be left out of this discussion) can be divided into five distinct periods. Before Columbus, who discovered the island for the Spanish Crown on his third journey in 1498, a few patches of the island were settled by indigenous Amerindians. The Spanish colonial period lasted three centuries, followed by British colonisation from 1797 and independence (with Tobago) since 1962. Towards the end of the admittedly half-hearted period of Spanish colonisation, Trinidad was settled by numerous French planters (whose descendants are still called 'French creoles'), and between 1847 and 1917, tens of thousands of Indians arrived to work in the cane fields, followed by traders of various origins. The contemporary population of Trinidad, briefly, reveals a great diversity of origins - African, Indian, European, Chinese and Lebanese.

Place names in Trinidad, accordingly, can be Spanish, French, Hindi, English or Carib. Their pronounciation is usually adapted to Trinidadian Creole (the Englishlexicon spoken vernacular), so that, for example, the urban agglomeration of San Juan between Port-of-Spain (English) and Arima (Carib) is pronounced, roughly, Sangua.

It might be expected that local place names in Trinidad would somehow reflect the island's turbulent history and patterns of settlement. In that case, dozens of villages in the central part of the island would have had Hindi names, which is not the case; as a matter of fact, Indian place names are notoriously underrepresented, given that a full forty per cent of the Trinidadian population has an Indian origin. The author V.S. Naipaul grew up in what was then a largely Hindi country town near the western coast between Port-of-Spain and San Fernando, the town's name being Chaguanas (which may sound vaguely Spanish or Hindi, but is in fact Carib.)

In fact, Trinidadian place names only reflect historical facts to a very limited degree. Carib names are scattered throughout the island, and there are French 
names in areas where few Frenchmen ever settled. For example, almost inexplicably, there is a cluster of villages and small towns in the southwest with names like La Brea, Point Fortin, Cap-de-Ville and so on, although the area was never settled by many French planters. Similarly, in the north-east, villages exclusively inhabited by Afro-Trinidadians are called Matelot, Grande Rivière and Sans Souci (which are all generic names for French colonial places). Names of diverse origins are juxtaposed in seemingly random ways. It is only a short drive from Rio Claro to Plaisance, and another short stretch down to Guayaguayare. Two of the upmarket suburbs in Port-of-Spain are called Diego Martin and Petit Valley, whereas Chaguaramas is a bit further west. Fullarton is very near Buenos Ayres, and a bit further up the road one passes both Siparia and Penal, villages whose etymology was never clarified to me, despite numerous attempts. A crossroads in south-central Trinidad is named, simply, Busy Corner. Just to give a sense of the layers of history characterising Trinidad. In Tobago, by contrast, where the population is almost exclusively Afro-Caribbean, most place names are English.

\section{[5] OSLO IN THE NEAR FUTURE}

With these three examples in mind, one may begin to consider future scenarios for European cities, such as Oslo, where the composition of the population is changing fast and dramatically. Past experiences of naming and renaming may also give a cue as to what the future may bring. In Trinidad, naming has taken place slowly as a result of changes in colonial regimes and the actual peopling of the island, which has taken place at an uneven pace essentially from the mid-18th century to the early 20th century. Thus, layers of history are revealed through the choice of names. In Toronto, changes in place names in response to changed demographics has begun to include new Canadians into the national identity, while the Iranian situation reveals a sense of self-identity largely dependent on the maintenance of an external enemy image. Toronto is self-consciously multicultural; Tehran is marked by a revulutionary rupture with the past; and Trinidad has a multilayered history which has slowly unfolded and left its traces in the names of localities and streets.

At the time of writing, about a quarter of Oslo's c. 600,000 inhabitants have a non-Norwegian origin (meaning that they are first- or second-generation migrants), and the proportion is bound to rise. Until now, there is scarcely a single visible onomastic indication of this change, although the public space has changed in a few ways through the building of a beautiful mosque in central-eastern Oslo, the emergence of scores of shops which in no uncertain way betray the cultural identities of their owners and the selection of goods. Since the Islamic revolution still seems to be a few years off, notwithstanding alarmist propaganda from the extreme right, the changes are likely to take some years, given what we know about the logic of street onomastics in this part of the world. Yet in 2006, the city's 
inhabitants got a preview of things to come through the re-naming of a modest street at Grønland in Oslo's immigrant-dense East End after the aforementioned, late Rubina Rana, the first non-white chair of the city's prestigious Constitution Day Committee.

The cumbersome, slow and bureaucratic process involved in changing place names in non-revolutionary contexts suggests that the naming of streets, squares and parks is not an innocent activity but one which simultaneously carries a deep cultural resonance and is a statement about official identity politics. To what extent street names carry strong connotations of significance for people's identity, is an empirical question. There is good reason to suppose that established street names are taken for granted, whereas new ones may be the subject of controversy. In Mauritius, I once lodged with an elderly lady and her son in Rue Swami Sivekananda, but Madame, a French-speaking white woman, insisted on retaining the colonial name, Rue Evenor Mamet, after a Franco-Mauritian poet, although the new name had de facto been established two decades earlier. There may be a parallel between this modest act of resistance and the confusing everyday mixing of old and new street names in Tehran. In this short analysis, I have tried to show that proper research on place names and, in particular, changes in place names, can indeed be a valuable and not least original contribution to the literature on belonging and identification, adding a new dimension to an otherwise crowded area.

\section{AKNOWLEDGEMENTS}

Thanks are due to Botolv Helleland and an external reader for useful suggestions to the first version of this article.

\section{REFERENCES}

Abramowicz, Z. \& L. Dacewicz. 2009. Changes in urbanonymy of north-eastern Poland in the context of statehood transformation. In Urban place names. Helsinki. Paper delivered at the symposium 'Urban place names', Helsinki 13-16 August 2009.

Ainiala, T. 2000. Ortnamn i förändring. Namn och Bygd. Tidskrift för nordisk ortnamnsforskning 25-40.

Alford, R. D. 1988. Naming and Identity: A Cross-cultural Study of Personal Naming Practices. New York: Harper \& Row.

Feizabad, A. K. \& E. Abbasi. 2009. How power structures affect place names in Iran. In Urban place names. Helsinki. Paper delivered at the symposium 'Urban place names', Helsinki 13-16 August 2009. 
Geertz, C. 1973. Person, time and conduct in Bali. In Geertz: The Interpretation of Cultures, 360-411. New York: Basic Books.

Parkin, D. (ed.). 1983. Semantic Anthropology. London: Academic Press.

Wetås, Å. 2000. Namneskiftet Kristiania-Oslo. Oslo: Novus.

AUTHOR CONTACT INFORMATION

Thomas Hylland Eriksen

Department of Social Anthropology

PO Box 1091 Blindern

0317 Oslo

Norway

t.h.eriksen@sai.uio.no 